\title{
Brexit is happening: what does it mean for science?
}

\begin{abstract}
At 11 p.m. on 31 January, the United Kingdom will leave the European Union. Although an 11-month transition period means the milestone will bring few immediate changes for researchers, the moment marks the start of negotiations over the country's future relationship with the bloc, including the United Kingdom's role in the EU's next seven-year research programme, Horizon Europe, which will start on 1 January 2021 and is set to be worth $€ 100$ billion (US\$110 billion). As Brexit begins, Nature takes a look at how 2020 negotiations could shake out for science.
\end{abstract}

What will change immediately after 11 p.m. on 31 January?

The United Kingdom will enter a transition period that will freeze its relationship with the EU for the rest of the year. Until 2021, scientists will still be free to take up jobs and travel between the United Kingdom and other EU countries. British researchers will be able to apply for European research funding and take part in exchange schemes.

\section{Will the United Kingdom seek to join Horizon Europe?}

On 20 January, UK science minister Chris Skidmore told Parliament that he wanted the UK to 'associate' with Horizon Europe - a status that could allow UK scientists to participate on similar terms to those they experience today. But he stressed that association would depend on the final shape and content of the programme, which has yet to be agreed by European legislators. Wider negotiations - including agreements on immigration - are also likely to affect whether this kind of association is possible. Any such agreement would normally come only after countries have agreed a trade deal.

What other factors will affect the United Kingdom's participation in Horizon Europe? Skidmore will have to convince the UK treasury that participation is worth the cost. The country has long taken more out of the EU research pot than it puts in, but that will almost certainly change, probably to a model in which the United Kingdom pays into the programme in line with what it receives.

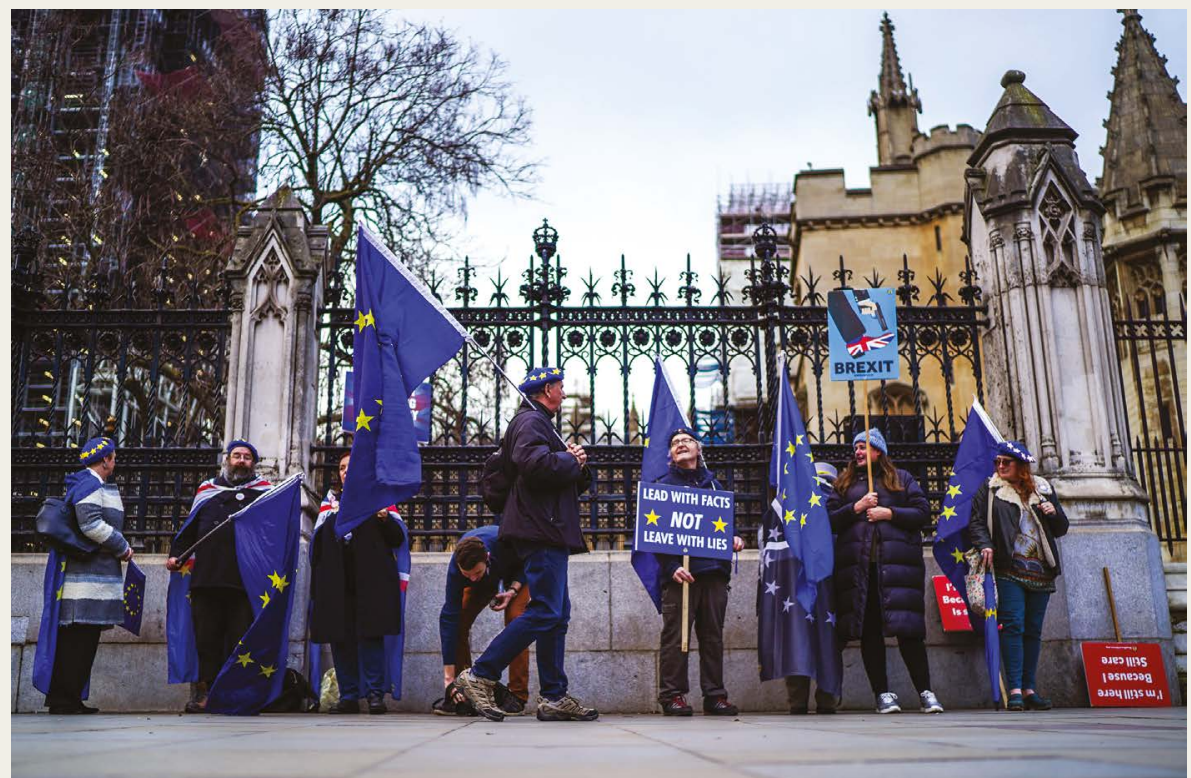

An anti-Brexit protest outside the Houses of Parliament in London.

How can the UK associate if freedom of movement between the United Kingdom and the EU ends?

Under the existing Horizon 2020 research programme, Norway and Switzerland - both non-EU countries that wanted to associate have to allow the free movement of people across their borders. This is something that the UK government has already ruled out. But the EU has suggested that it might be more flexible on the conditions of entry for the next programme. Beth Thompson, head of UK and EU Policy at the London-based biomedicalresearch funder Wellcome, says a UK system that guarantees mobility for researchers - such as the fast-track visa for researchers that the UK government announced on 27 January - could be enough to secure an agreement. The Global Talent visa route will open from 20 February, upgrading and expanding the underused 'exceptional talent' visa and allowing the country's main research funder, UK Research and Innovation, to endorse candidates.

Can the scientific relationship between the United Kingdom and the EU be agreed by the end of the transition period on 31 December? It's possible, says Thompson, but it will be a challenge. A mock negotiation exercise carried out by Wellcome and the Brussels-based economic think tank Bruegel found that there is only a "remote" chance that the United Kingdom and the EU will be able to agree a wider trade deal in 11 months. But the report, published on 28 January, concluded that it might be possible to agree an unprecedented standalone deal for science. For this to happen, both sides would need to agree to make an exception for science, for example by establishing special visas for researchers and setting up a system that allows UK organizations to opt in to EU data standards.

\section{What if the United Kingdom doesn't} manage to join Horizon Europe before the end of 2020?

This would be disruptive. "Both the UK and EU will lose out," warns Thompson. Without association, UK researchers would be able to take part in Horizon Europe only as members of a 'third country': they could participate in some EU-funded projects but not lead them, and only if the government agreed to pay their costs. If there is no wider trade deal, it could affect travel, data sharing and laboratory supplies. UK researchers will almost certainly need visas to take up jobs in EU nations, whether or not the United Kingdom can craft a new immigration system in time.

By Elizabeth Gibney 